\title{
A natural heating experiment: Phenotypic and genotypic responses of plant phenology to geothermal soil warming
}

\author{
Alicia Valdés $^{1,2}$ (D) | Bryndís Marteinsdóttir ${ }^{3}$ (D) | Johan Ehrlén ${ }^{1,2}$
}

${ }^{1}$ Department of Ecology, Environment and Plant Sciences, Stockholm University, Stockholm, Sweden

${ }^{2}$ Bolin Centre for Climate Research, Stockholm University, Stockholm, Sweden ${ }^{3}$ Institute of Life and Environmental Sciences, University of Iceland, Reykjavík, Iceland

\section{Correspondence}

Alicia Valdés, Department of Ecology, Environment and Plant Sciences, Stockholm University, Stockholm, Sweden.

Email: aliciavaldes1501@gmail.com

\section{Present address}

Bryndís Marteinsdóttir, The Soil Conservation Service of Iceland, Hella, Iceland.

Funding information The Energy research fund from the National power Company of Iceland; University of Iceland

\begin{abstract}
Under global warming, the survival of many populations of sedentary organisms in seasonal environments will largely depend on their ability to cope with warming in situ by means of phenotypic plasticity or adaptive evolution. This is particularly true in high-latitude environments, where current growing seasons are short, and expected temperature increases large. In such short-growing season environments, the timing of growth and reproduction is critical to survival. Here, we use the unique setting provided by a natural geothermal soil warming gradient (Hengill geothermal area, Iceland) to study the response of Cerastium fontanum flowering phenology to temperature. We hypothesized that trait expression and phenotypic selection on flowering phenology are related to soil temperature, and tested the hypothesis that temperature-driven differences in selection on phenology have resulted in genetic differentiation using a common garden experiment. In the field, phenology was related to soil temperature, with plants in warmer microsites flowering earlier than plants at colder microsites. In the common garden, plants responded to spring warming in a counter-gradient fashion; plants originating from warmer microsites flowered relatively later than those originating from colder microsites. A likely explanation for this pattern is that plants from colder microsites have been selected to compensate for the shorter growing season by starting development at lower temperatures. However, in our study we did not find evidence of variation in phenotypic selection on phenology in relation to temperature, but selection consistently favoured early flowering. Our results show that soil temperature influences trait expression and suggest the existence of genetically based variation in flowering phenology leading to counter-gradient local adaptation along a gradient of soil temperatures. An important implication of our results is that observed phenotypic responses of phenology to global warming might often be a combination of shortterm plastic responses and long-term evolutionary responses, acting in different directions.
\end{abstract}

\section{KEYWORDS}

climatic variation, geothermal ecosystems, Iceland, local adaptation, microclimate, phenotypic plasticity, phenotypic selection, plant phenology 


\section{1 | INTRODUCTION}

Climate change is causing significant increases in temperature across the world, with warming being most pronounced towards Arctic regions (IPCC, 2014), and with important effects on biodiversity (Bellard, Bertelsmeier, Leadley, Thuiller, \& Courchamp, 2012). Species responses to global warming (Parmesan, 2006; Parmesan \& Yohe, 2003) might involve distributional changes to track appropriate conditions in space (range shifts), or changes in the timing of life cycle events (phenological shifts) to keep up with seasonally changing abiotic factors. Most observations of responses to climate change have concerned alterations in phenology (Cleland, Chuine, Menzel, Mooney, \& Schwartz, 2007; Ibáñez et al., 2010; Parmesan, 2006), and such responses should be critical for survival at high latitudes, where the possibilities for dispersal to colder areas are restricted. Individuals can change their phenology in response to warming through phenotypic plasticity (i.e. the ability of a given genotype to express different phenotypes in different environments, Agrawal, 2001) and populations can respond evolutionary through changes in their genetic structure (Anderson, Inouye, McKinney, Colautti, \& Mitchell-Olds, 2012; Franks, Weber, \& Aitken, 2014). Observed phenotypic responses to warming have often been argued to be mainly due to phenotypic plasticity (Hoffmann \& Sgrò, 2011; Leblans et al., 2017; Merilä \& Hendry, 2014), and only to a smaller extent due to evolutionary changes (Franks, Sim, \& Weis, 2007; Lavergne, Mouquet, Thuiller, \& Ronce, 2010).

The seasonal timing of life cycle events determines how an organism interacts with the surrounding environment, and variation in phenology can have strong effects on survival and reproduction. Higher spring temperatures caused by current climate change have been shown to cause shifts in timing and length of the growing season, with an earlier start being resposible for most of these shifts (Linderholm, 2006). Higher temperatures and the subsequent advancement of the growing season might condition the timing of life cycle events of an organism in a given year, leading to phenotypic plasticity in phenology as a consequence of direct effects of climate on physiological and developmental rates. However, variation in climate can also influence natural selection on timing, and differential selection might lead to genetic differentiation of populations (Anderson et al., 2012; Franks et al., 2007; Visser, 2008). Local adaptation through genetic responses along climatic gradients can be either co-gradient, when genetic and environmental influences on a phenotype act in the same direction, counter-gradient when they act in opposite directions, or show no relation with the climatic gradient (Conover \& Schultz, 1995). Counter-gradient variation would be expected if growing season length is the only factor influencing selection on phenology. In this case, cold environments with short growing seasons (e.g. high latitudes or altitudes) would select for a higher sensitivity of developmental rates to spring warming, leading to the evolution of faster developing genotypes in cold environments than in warm environments. Individuals from cold environments would thus be able to start development at lower temperatures than individuals from warm environments when grown under similar conditions during spring.

The effects of climate warming on plant phenology have usually been examined empirically, by examining patterns of local adaptation along latitudinal (Toftegaard et al., 2016) or altitudinal gradients (Frei, Ghazoul, Matter, Heggli, \& Pluess, 2014), or by performing experiments using open-top chambers or other warming devices (Arft et al., 1999; Wolkovich et al., 2012). Despite the convenience of latitudinal and altitudinal gradients as natural set-ups to study species' responses to climate warming (De Frenne et al., 2013; Körner, 2007), they suffer from the limitation that other environmental factors often covary with temperature along these gradients. Experimental manipulation of temperatures allows us to dissect temperature effects from confounding environmental factors that covary with temperature in natural conditions. However, experiments are usually performed at smaller spatial scales, and are often associated with unintended disturbances in abiotic or biotic conditions (e.g. light availability, wind speed, soil moisture and biotic interactions) caused by environmental manipulations, that can result in the underprediction of phenological responses to warming (Wolkovich et al., 2012). Moreover, the relatively short duration of most experiments does not allow the examination of long-term evolutionary responses. Geothermally heated ecosystems (Leblans et al., 2017; O'Gorman et al., 2014) provide unique "natural laboratories" for studying long-term responses to temperature increase, avoiding many of the limitations of both larger-scale temperature gradients and experimental designs. As some of these systems have been warmed for a long time (e.g. more than 50 years of continuous warming on Icelandic sub-arctic grasslands, Leblans et al., 2017; O'Gorman et al., 2014), they allow the evaluation of the long-term effects of warming on plant phenology. Moreover, temperature differences in these systems are large (e.g. $0-50^{\circ} \mathrm{C}$, O'Gorman et al., 2014), and occur over small spatial scales, reducing variation in other environmental factors (Leblans et al., 2017; Richardson, Urban, Bolnick, \& Skelly, 2014; Robinson, McLaughlin, Marteinsdóttir, \& O'Gorman, 2018). Combinations of observational studies on natural geothermal soil warming gradients with common garden experiments should thus constitute a very powerful approach to assess plastic and genetic responses of plant phenology to warming.

In this study, we investigated the relationship between small-scale variation in geothermal soil warming and phenotypic and genotypic differences in flowering phenology, using the perennial herb Cerastium fontanum in sub-arctic Icelandic grasslands where large differences in growing season length along natural geothermal soil warming gradients have been documented (Leblans et al., 2017; Perron, 2017). Because we expected differences in other environmental factors to be small, we predicted that growing season length should strongly influence selection on plant flowering phenology, leading to counter-gradient variation (Conover \& Schultz, 1995) in genetic responses to warming. More specifically, we hypothesized that: (a) colder microsites are associated with a later flowering phenology in the field, (b) natural selection for early flowering is stronger at colder microsites with shorter growing seasons, and as a consequence of such differences in 
selection, (c) there are genetically based differences in phenology that are related to soil temperature at the microsite of origin, and these differences are in a counter-gradient fashion, with plants originating from colder microsites flowering earlier.

\section{2 | MATERIALS AND METHODS}

\section{1 | Study system}

The study was carried out in the Hengill geothermal area, $40 \mathrm{~km}$ east of Reykjavik, Iceland (64 $3^{\prime} 11^{\prime \prime} \mathrm{N}, 21^{\circ} 18^{\prime} 16^{\prime \prime} \mathrm{W} ; 360 \mathrm{~m}$ a.s.l.). This area is located at the base of the Hengill volcanic system, near to the Hrómundartindur and Hveragerði volcanic systems, where the Reykjanes Volcanic Zone, the West Volcanic Zone and the South Iceland Seismic Zone converge (Saemundsson, 1992; Zakharova \& Spichak, 2012). The underlying bedrock of the study site contains geothermal channels originating from high volcanic activity common at tectonic boundaries (Zakharova \& Spichak, 2012). These channels warm the water and soil through radiative heating (Gudmundsdottir et al., 2011; Saemundsson, 1995). The soil temperatures range from average ambient to over $20^{\circ} \mathrm{C}$ above ambient in some areas with little to no warming on the air temperature (O'Gorman et al., 2014). The study area covers approximately $0.5 \mathrm{~km}^{2}$ where the main vegetation type consists of unmanaged, but grazed, subarctic grassland. Grassland ecosystems cover ca. $40 \%$ of the global terrestrial surface (of which $25 \%$ is at northern high latitudes, Chapin, Matson, \& Vitousek, 2011), and temperature has been suggested to be an important driver of grassland phenology (Cleland, Chiariello, Loarie, Mooney, \& Field, 2006; Frei et al., 2014). Apart from soil temperature, there are no significant changes in other abiotic factors (e.g. soil chemistry, elevation) in our study area (Robinson et al., 2018). This system has been heated for over 50 years (probably much longer, (Saemundsson, 1967), offering a unique natural laboratory for studying the long-term effects of warming.

For this study, we focused on the effects of warming on flowering phenology of Cerastium fontanum, a short-lived clonal perennial herb that flowers in June and July in the study area. It can be crossor self-pollinated and it shows unspecialized seed dispersal (Fitter \& Peat, 1994; Kristinsson, 1998). We chose this study species because it occurs over a relatively wide range of temperatures, and because it can be easily grown from seeds.

\subsection{Data collection}

We collected data on soil temperature and flowering phenology in 2015 (100 plants over an area of $0.25 \mathrm{~km}^{2}$ ) and 2017 (420 plants over an area of $0.5 \mathrm{~m}^{2}$ ). In each of these two years, plant individuals were marked before the start of flowering and followed throughout the entire season. The marked plants were different in 2015 and 2017. Soil temperature was measured once in the immediate vicinity $(<2 \mathrm{~cm})$ of each of the plants with a soil thermometer. Temperature was measured at a depth of $10 \mathrm{~cm}$, i.e. at the level of the plant roots, which is little affected by air temperature. Therefore, these temperature measurements reflect long-term differences in soil temperature, and are not influenced by weather during the day of measurement. Measures of plant phenology differed among the two study years. In 2015, flowering phenology was estimated based on the reproductive development at the day of recording (between June 30 and July 3), and coded as a binomial variable, being 1 in plants that had no open flowers, and 0 in plants that had at least 1 flower open on that day. All plants that had no open flowers had buds in different stages of development and none of them had wilted flowers, meaning that all plants that had no open flowers at the day of recording would flower later in the season. In 2017, plant reproductive development was followed on a weekly basis from the beginning of June, and first flowering date (FFD, the date when the first open flower was observed) was used as an estimate of flowering phenology. In both years, higher values of the phenology variable represent a later flowering phenology. In 2017, the numbers of flowers and fruits per plant were also counted, and a sample of 1-8 fruits was collected. The number of seeds in these fruits was counted afterwards in the lab, and the number of seeds per plant was calculated by multiplying the number of fruits per plant by the mean number of seeds per fruit.

To extract seeds for sowing, we collected up to three fruits from each marked plant in 2015. The seeds were sown in the greenhouse in January 2016, and plants were transferred to a common garden at Stockholm University (mean annual air temperature $=8^{\circ} \mathrm{C}$ for 2017) in June 2016. None of the plants flowered in 2016. In 2017, reproductive development of these plants in the common garden was followed on a regular basis from the beginning of May until the last flower was open (the presence or absence of flowers was recorded on May 18th, 21st, 24th and 28th, and on June 2nd, 9th, 16th and 18th). FFD (converted to Julian date) was used as an estimate of flowering phenology. A total of 540 plants corresponding to 98 maternal families survived and flowered in the common garden in 2017, and the number of flowering offspring per mother plant (i.e. plant flowering in the field from which seeds were collected) ranged from 1 to 10 plants (mean $\pm S D=5.5 \pm 2.7$ ).

\section{3 | Statistical analyses}

To assess if local soil temperature is associated with an earlier phenology in the field, we fitted generalized linear models of flowering phenology against soil temperature in both study years. We used a binomial model for 2015 (as phenology was measured as a binomial response variable, non-flowering vs. flowering at the time of recording) and a linear model for 2017 (as FFD showed an approximately normal distribution).

To test if phenotypic selection on flowering phenology depended on soil temperature, we performed a linear selection gradient analysis (Lande \& Arnold, 1983) with the data from 2017. Fitness, in terms of the number of seeds per plant, was used as the response variable, and phenology, flower number, soil temperature and the interaction phenology $\times$ soil temperature were included as fixed predictors. Flower number was included as a condition trait, i.e. a trait 
which is likely to be correlated with plant resource state, in order to get better estimates of selection on phenology, and to reduce the bias caused by environmental covariance (Rausher, 1992). Fitness was relativized by dividing each value by the mean, and phenology and flower number were standardized by subtracting their mean and dividing by their standard deviation. We also run the same model without the interaction term in order to assess the overall direction of selection on phenology.

To assess if phenology in a common environment differs among maternal families, and is related to soil temperature at the microsite of origin of the mother plant, we first tested if flowering phenology in the common garden in 2017 differed among plants with different mothers. For this, we fitted a linear mixed model with phenology in the common garden (FFD converted to Julian date) as the response variable and mother as random effect. As we found significant differences in phenology among plants with different mothers (see Section 3), we then evaluated if these differences were related to soil temperature at the origin of the mother plant by fitting another linear mixed model with phenology in the common garden as the response, soil temperature at the origin as a fixed effect, and mother as random effect. In each case, we tested the significance of the random effect using a likelihood ratio test, comparing a model with the random effect to the same model without the random effect.

Statistical analyses were carried out in R ver. 3.5.0 (R Core Team, 2018).

\section{3 | RESULTS}

Soil temperature ranged from 6.8 to $33.7^{\circ} \mathrm{C}$ in 2015 , with a mean value of $18.2^{\circ} \mathrm{C}$, and from 4.1 to $45.5^{\circ} \mathrm{C}$ in 2017 , with a mean value

TABLE 1 Results of generalized linear models assessing the effects of soil temperature on Cerastium fontanum flowering phenology, measured as the probability of not having flowered at the day of recording in 2015 (binomial model) and as the first flowering date (converted to Julian date) in 2017 (linear model)

\begin{tabular}{lrlllll} 
Year & \multicolumn{1}{c}{$\boldsymbol{N}$} & Estimate & $\mathrm{SE}$ & $\boldsymbol{z} / \boldsymbol{t}$ & $\boldsymbol{p}$ & $\boldsymbol{R}^{2}$ \\
\hline 2015 & 96 & -0.111 & 0.036 & -3.11 & 0.002 & 0.022 \\
2017 & 300 & -0.189 & 0.068 & -2.80 & 0.006 & 0.153 \\
\hline
\end{tabular}

of $14.4^{\circ} \mathrm{C}$. Soil temperature showed a large variation within short distances; soil temperatures of plants located $1 \mathrm{~m}$ apart sometimes differed by $10^{\circ} \mathrm{C}$, and plants located $10 \mathrm{~m}$ apart differed with up to $25^{\circ} \mathrm{C}$.

Higher soil temperature was associated with an earlier phenology in both study years, although temperature explained only a relatively small part of the variability in phenology (Table 1). In 2015, the probability of not having flowered at the day of recording decreased with soil temperature (Figure 1a), and in 2017, FFD was earlier with higher soil temperatures (Figure 1b).

The relationship between plant phenology and fitness did not depend on soil temperature (the effect of the interaction phenology $\times$ soil temperature was not significant, Table 2a, Figure $2 b$ ). When the interaction was removed from the model, fitness increased with an earlier flowering (Table 2b, Figure 2a).

Phenology in the common garden differed among plants with different mothers (Table 3a), and these differences were related to soil temperature at the microsite of origin of the mother plant (Table 3b). As hypothesized, differences in phenology followed a counter-gradient pattern; plants with mothers from colder microsites flowered earlier than plants with mothers from warmer microsites (Figure 3).

\section{DISCUSSION}

In this study, geothermally induced small-scale variation in soil temperatures was related to both phenotypic and genotypic variation in flowering phenology of the grassland plant Cerastium fontanum. Plants at warmer microsites flowered relatively earlier than plants at colder microsites. In contrast, plants grown in a common environment responded to spring warming following a counter-gradient pattern: plants originating from warmer microsites flowered later than those originating from colder microsites. Yet, we were not able to document the corresponding pattern of phenotypic selection on phenology (i.e. stronger selection for early flowering at colder microsites) along the temperature gradient in one study year. From a methodological perspective, our study highlights the suitability of geothermal systems for studying ecological and evolutionary responses to global warming. (a) 2015

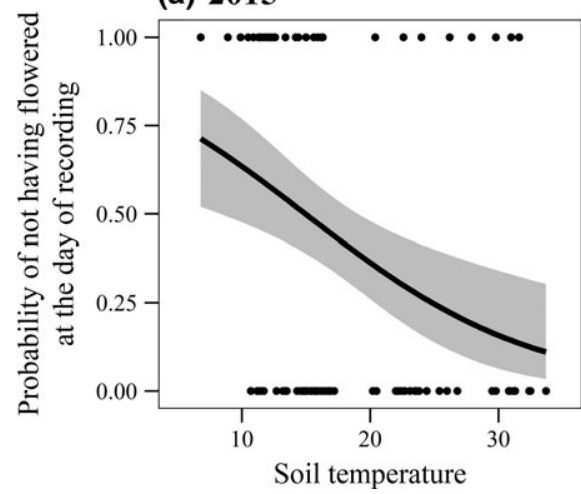

Soil temperature (b) 2017

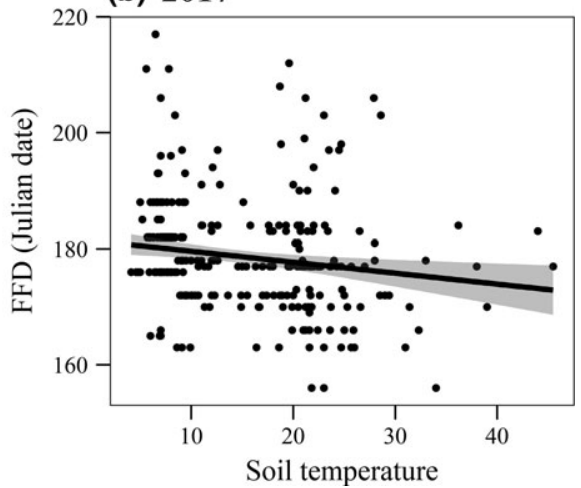

FIGURE 1 Effect of soil temperature on flowering phenology of Cerastium fontanum, measured as (a) the probability of not having flowered at the day of recording in 2015 and (b) the first flowering date (FFD) converted to Julian date in 2017. In both cases, higher values representing a later flowering phenology. Lines show a binomial model fit in (a), and a linear model fit in (b) 
Our results show a plastic response of $C$. fontanum flowering phenology to natural differences in local soil temperature, with earlier flowering being associated with warmer microsites in two different years. The start of flowering in plants has been reported to advance with increasing temperatures along natural temperature gradients or in response to experimental manipulations (De Frenne et al., 2011; Menzel, Sparks, Estrella, \& Roy, 2006; Price \& Waser, 1998), and this study highlights that responses to temperature differences also happen over small spatial scales. Previous studies have suggested that the response of flowering time to temperature is mainly due to phenotypic plasticity, which is controlled by plant physiology, and thus can be relatively rapid (De Frenne et al., 2011; Frei et al., 2014). The earlier flowering phenology at warmer microsites along the temperature gradient observed in this study is in agreement with a reported advancement in the start of the growing season in response to warming at a nearby site (Leblans et al., 2017). Previous studies with northern plant species have shown that the physiological control mechanisms of the start of the growing

TABLE 2 (a) Results of a selection gradient analysis assessing the effects of flowering phenology (first flowering date) and flower number of Cerastium fontanum, as well as soil temperature and the interaction phenology $\times$ soil temperature on plant fitness in 2017 ( $N=193$ plants where both traits and fitness data was available, AIC =770.6). (b) Results of a similar selection gradient analysis without the interaction term (AIC =769.2). Fitness was estimated by the number of seeds per plant and relativized before analyses. Phenology and number of flowers were standardized before analyses

Estimate SE $t \quad p$

(a) Model with interaction phenology $\times$ soil temperature

\begin{tabular}{lllll} 
Phenology & -0.423 & 0.275 & -1.54 & 0.126 \\
\hline Number of flowers & -0.160 & 0.135 & -1.18 & 0.239 \\
\hline Soil temperature & -0.041 & 0.020 & -2.11 & 0.036 \\
\hline Phenology:Soil temperature & -0.014 & 0.018 & -0.76 & 0.446
\end{tabular}

(b) Model without interaction phenology $\times$ soil temperature

\begin{tabular}{|lrrrr|}
\hline Phenology & -0.603 & 0.143 & -4.23 & $<0.001$ \\
\hline Number of flowers & -0.171 & 0.134 & -1.27 & 0.205 \\
\hline Soil temperature & -0.037 & 0.019 & -1.98 & 0.049 \\
\hline
\end{tabular}

season are to a larger extent driven by heat accumulation (e.g. Growing Degree Days), than by light regime (Bennie, Kubin, Wiltshire, Huntley, \& Baxter, 2010). Changes in the persistence of snow cover are also an important driver of flowering time in high latitude and high altitude ecosystems (Inouye \& McGuire, 1991). Therefore, the earlier flowering of $C$. fontanum in warmer microsites could be induced both by higher heat accumulation and earlier snowmelt in these microsites.

Our results not only provide evidence of phenotypic responses to temperature variation, but also suggest the existence of an evolutionary response to geothermal soil warming. Flowering phenology in a common environment differed among plants with different mothers, and this variation was related to soil temperature at the microsite of origin of the mother plant, suggesting the existence of genetic differentiation in flowering time related to temperature variation. Because we used seeds collected from plants grown in the field, some of the observed variation in flowering phenology in the common garden might potentially be due to non-genetic maternal effects (Galloway, 2005; Rossiter, 1996), rather than due to additive genetic variation. The maternal environment may influence the phenotype of the offspring directly, through seed provisioning or through plasticity of traits in the maternal plant that influence offspring trait expression (Galloway, 2005). The plants used in our common garden study were grown for two years in a common environment before recording their flowering phenology, which should have decreased, although not eliminated, maternal effects. Moreover, maternal effects are usually most pronounced in early life-history stages (Rossiter, 1996), and thus probably not highly affecting our results. A third reason why maternal effects appear to be less likely to qualitatively have influenced our findings, is that the relationship between temperature at the microsite of origin and flowering phenology in the common garden was in the opposite direction to the pattern observed in the field.

In the common garden, plants originating from environments with longer growing seasons (i.e. warmer microsites) started flowering relatively later than plants originating from environments with shorter growing seasons (i.e. colder microsites). This is in contrast with the pattern in the field, where plants at warmer microsites flowered relatively earlier than plants at colder microsites. These
FIGURE 2 Effect of standardized first flowering date (FFD) on relative fitness of Cerastium fontanum, measured as the relative number of seeds per plant. (a) Linear model fit for the overall relationship. (b) Linear model fits for different soil temperatures, from cold (light color) to warm (dark color) microsites. Note the different scales on the $y$ axes in (a) and (b)
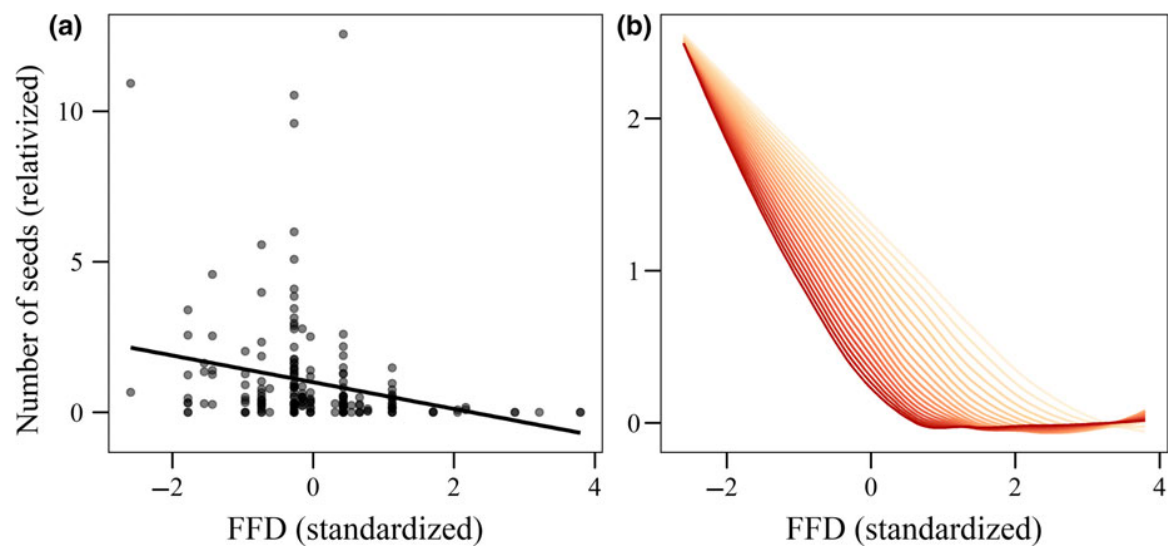
TABLE 3 Results of linear mixed models on flowering phenology (first flowering date) in the common garden, including effects of (a) mother (random effect), and (b) mother (random effect) and soil temperature at the origin of the mother (fixed effect). The significance of the random effects was tested using a likelihood ratio test (LRT), comparing a model with the random effects to the same model without the random effects. $R^{2}$ marg and $R^{2}$ cond are the marginal and conditional pseudo- $R^{2}$ (representing, respectively, the variance explained by the fixed effects and by the entire model, Nakagawa \& Schielzeth, 2013)

\begin{tabular}{|c|c|c|c|c|c|c|c|c|}
\hline Model & Predictor variable & LRT $\chi^{2}$ & & & $p$ & AIC & $R_{\text {marg }}^{2}$ & $R_{\text {cond }}^{2}$ \\
\hline (a) & Mother (random) & 65.54 & & & $<0.001$ & 3516.9 & 0 & 0.303 \\
\hline \multirow[t]{2}{*}{ (b) } & Mother (random) & 25.69 & & & $<0.001$ & 3479.5 & 0.151 & 0.298 \\
\hline & Soil temperature at origin (fixed) & 0.401 & 0.055 & 7.24 & $<0.001$ & & & \\
\hline
\end{tabular}

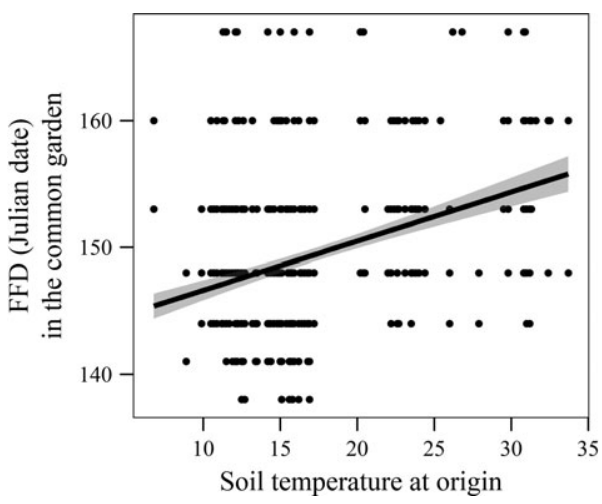

FIGURE 3 Effect of soil temperature at the origin of the mother plant on flowering phenology of Cerastium fontanum in the common garden in 2017. Phenology was measured as the first flowering date (FFD) converted to Julian date, with higher values representing a later flowering phenology. A linear model fit is shown

different responses have two important implications. First, they suggest that the effect of temperature on phenology in the field is largely plastic. Second, the observed pattern constitutes an example of counter-gradient variation in local adaptation occurring over a very small spatial scale (Conover \& Schultz, 1995). The results of our common garden study agree with results obtained over larger-scale temperature gradients. For example, plants originating from northern populations usually flower before plants from southern populations when grown in a common environment (Kollmann \& Bañuelos, 2004; Olsson \& Ågren, 2002). In cold environments, a later start and a shorter duration of the growing season constrains the period available for growth and fruit maturation, and should select for fast development and early flowering, and result in plants evolving to start development at lower temperatures. The existence of genetically determined variation in flowering phenology over small spatial scales in our study contributes to the increasing evidence of the importance of microgeographic adaptation (Richardson et al., 2014; Skelly, 2004). For local adaptation to occur, the strength of selection has to exceed the homogenizing effect of gene flow (García-Ramos \& Kirkpatrick, 1997). Cerastium fontanum reproduces with cross-pollination or selfing. In our study site selfing is likely very common as it has been demonstrated that selfing rates increase with latitude and altitude (Bliss, 1962; Medan et al., 2002). Moreover, phenological assortative mating can promote local adaptation because the differences in flowering time might lead to partial temporal reproductive barriers, which should reduce gene flow (Soularue \& Kremer, 2014; Weis, 2015; Weis \& Kossler, 2004). In addition to pollen dispersal, gene flow is likely to occur through seed dispersal. However, seeds of $C$. fontanum lack mechanisms for dispersal and are likely to mostly be dispersed over relatively short distances (Fitter \& Peat, 1994; Kristinsson, 1998). Taken together, gene flow through pollen and seed dispersal in the studied population appears to be limited and not strong enough to counteract selection and prevent the evolutionary divergence of plants in cold and warm microsites. Genetic differentiation at such small spatial scales might allow to buffer species against future climatic changes. For instance, plants exposed to locally warm temperatures might supply the adaptive alleles that promote more widespread adaptation to warming temperatures (Richardson et al., 2014), allowing species to persist under future climatic conditions.

Although the results of our common garden experiment suggest the existence of an evolutionary response to geothermal soil warming which should be the consequence of differences in phenotypic selection among cold and warm microsites, we found no evidence of such variation in selection. Contrary to our expectation of natural selection for early flowering being stronger in colder microsites, selection favored early flowering irrespective of soil temperature. On the one hand, the strenght and direction of phenotypic selection in natural populations has been shown to vary temporally (Siepielski, DiBattista, \& Carlson, 2009), and the conditions favouring stronger selection for early flowering in colder microsites might be present in some years, but absent in others. For example, in years with very cold springs or late spring frosts, where cold temperatures and frost damage could prevent pollination and fruit set in early flowering plants (Inouye, 2000), selection for early flowering in colder microsites might be weaker than it would be in years with average spring conditions. On the other hand, our results agree with previous work showing the persistence of phenotypic selection for early flowering in natural populations (Austen, Rowe, Stinchcombe, \& Forrest, 2017; Munguía-Rosas, Ollerton, Parra-Tabla, \& De-Nova, 2011). One reason for this might be that both early flowering and fitness are influenced by the environment, i.e. environmental covariance (Ehrlén, 2015; Stinchcombe et al., 2002). Individuals growing at the most 
favourable microsites may have more resources, and therefore, are able to both flower earlier and to produce more seeds.

An important implication of the results of our study is that plants are likely to respond to higher temperatures not only plastically, but also genetically, and that observed responses will often be a combination of short-term plastic responses and long-term evolutionary responses. Moreover, our results suggest that phenotypic and genotypic responses to warming might act in different directions. In a global warming context, adaptation to climate change may be especially important for the persistence of flowering plant species in high-latitude areas because their limited dispersal ability and the proximity to their range edge may prevent them from shifting their distribution to more favourable climates. Climate exerts strong selective pressure on natural populations, and the results of our study highlight that in order to correctly interpret observed phenotypic responses to past climate change in seasonal environments, as well as to predict responses to future climate change, we need to account for the fact that adaptive evolution and changes in population genetic composition might be as important as the instantaneous plastic responses.

\section{ACKNOWLEDGEMENTS}

We thank Vigdís Freyja Helmutsdóttir, Rán Finnsdóttir, Nia S. Perron, Laura Lecacheux and Katarina Fast Ehrlén for assistance in the field, Malin Borg and Ebba Tamm for help in the lab, greenhouse and common garden and Arthur E. Weis and an anonymous referee for comments on a previous version of the manuscript. We acknowledge funding from the Energy research fund from the National power Company of Iceland and University of Iceland post-doctoral grant to B.M.

\section{ORCID}

Alicia Valdés (iD https://orcid.org/0000-0001-9281-2871

BryndísMarteinsdóttir (iD https://orcid.org/0000-0003-3779-7327

\section{REFERENCES}

Agrawal, A. A. (2001). Phenotypic plasticity in the interactions and evolution of species. Science, 294(5541), 321-326. https://doi.org/10. 1126/science.1060701.

Anderson, J. T., Inouye, D. W., McKinney, A. M., Colautti, R. I., \& MitchellOlds, T.. (2012). Phenotypic plasticity and adaptive evolution contribute to advancing flowering phenology in response to climate change. Proceedings of the Royal Society of London B: Biological Sciences, 279(1743), 3843-3852. https://doi.org/10.1098/rspb.2012.1051

Arft, A. M., Walker, M. D., Gurevitch, J., Alatalo, J. M., Bret-Harte, M. S., Dale, M., ... Wookey, P. A. (1999). Responses of tundra plants to experimental warming: Meta-analysis of the International Tundra Experiment. Ecological Monographs, 69(4), 491-511. https://doi.org/ 10.1890/0012-9615(1999) 069[0491:ROTPTE]2.0.CO;2.

Austen, E. J., Rowe, L., Stinchcombe, J. R., \& Forrest, J. R. K. (2017). Explaining the apparent paradox of persistent selection for early flowering. New Phytologist, 215(3), 929-934. https://doi.org/10. 1111/nph.14580.

Bellard, C., Bertelsmeier, C., Leadley, P., Thuiller, W., \& Courchamp, F. (2012). Impacts of climate change on the future of biodiversity.
Ecology Letters, 15(4), 365-377. https://doi.org/10.1111/j.14610248.2011.01736.x.

Bennie, J., Kubin, E., Wiltshire, A., Huntley, B., \& Baxter, R. (2010). Predicting spatial and temporal patterns of bud-burst and spring frost risk in north-west Europe: The implications of local adaptation to climate. Global Change Biology, 16(5), 1503-1514. https://doi.org/10. 1111/j.1365-2486.2009.02095.x.

Bliss, L. C. (1962). Adaptations of arctic and alpine plants to environmental conditions. Arctic, 15(2), 117-144. https://doi.org/10.14430/arctic 3564

Chapin, F. S. C. III, Matson, P. A., \& Vitousek, P. (2011). Principles of terrestrial ecosystem ecology, 2nd ed. New York, NY: Springer-Verlag. www.springer.com/la/book/9781441995032

Cleland, E. E., Chiariello, N. R., Loarie, S. R., Mooney, H. A., \& Field, C. B. (2006). Diverse responses of phenology to global changes in a grassland ecosystem. Proceedings of the National Academy of Sciences, 103 (37), 13740-13744. https://doi.org/10.1073/pnas.0600815103.

Cleland, E. E., Chuine, I., Menzel, A., Mooney, H. A., \& Schwartz, M. D. (2007). Shifting plant phenology in response to global change. Trends in Ecology \& Evolution, 22(7), 357-365. https://doi.org/10.1016/j.tree. 2007.04.003

Conover, D. O., \& Schultz, E. T. (1995). Phenotypic similarity and the evolutionary significance of countergradient variation. Trends in Ecology \& Evolution, 10(6), 248-252. https://doi.org/10.1016/S01695347(00)89081-3.

De Frenne, P., Brunet, J., Shevtsova, A., Kolb, A., Graae, B. J., Chabrerie, O., ... Verheyen, K. (2011). Temperature effects on forest herbs assessed by warming and transplant experiments along a latitudinal gradient. Global Change Biology, 17(10), 3240-3253. https://doi.org/ 10.1111/j.1365-2486.2011.02449.x.

De Frenne, P., Graae, B. J., Rodríguez-Sánchez, F., Kolb, A., Chabrerie, O., Decocq, G., ... Verheyen, K. (2013). Latitudinal gradients as natural laboratories to infer species' responses to temperature. Journal of Ecology, 101(3), 784-795. https://doi.org/10.1111/1365-2745. 12074.

Ehrlén, J. (2015). Selection on flowering time in a life-cycle context. Oikos, 124(1), 92-101. https://doi.org/10.1111/oik.01473.

Fitter, A. H., \& Peat, H. J. (1994). The Ecological Flora Database. Journal of Ecology, 82(2), 415-425. 10.2307/2261309 (http://www.ecoflora.c o.uk)

Franks, S. J., Sim, S., \& Weis, A. E. (2007). Rapid evolution of flowering time by an annual plant in response to a climate fluctuation. Proceedings of the National Academy of Sciences, 104(4), 1278-1282. https://doi.org/10.1073/pnas.0608379104.

Franks, S. J., Weber, J. J., \& Aitken, S. N. (2014). Evolutionary and plastic responses to climate change in terrestrial plant populations. Evolutionary Applications, 7(1), 123-139. https://doi.org/10.1111/eva.12112.

Frei, E. R., Ghazoul, J., Matter, P., Heggli, M., \& Pluess, A. R. (2014). Plant population differentiation and climate change: Responses of grassland species along an elevational gradient. Global Change Biology, 20(2), 441-455. https://doi.org/10.1111/gcb.12403.

Galloway, L. F. (2005). Maternal effects provide phenotypic adaptation to local environmental conditions. New Phytologist, 166(1), 93-100. https://doi.org/10.1111/j.1469-8137.2004.01314.x.

García-Ramos, G., \& Kirkpatrick, M. (1997). Genetic models of adaptation and gene flow in peripheral populations. Evolution, 51(1), 21-28. https://doi.org/10.1111/j.1558-5646.1997.tb02384.x.

Gudmundsdottir, R., Gislason, G. M., Palsson, S., Olafsson, J. S., Schomacker, A., Friberg, N., ... Moss, B. (2011). Effects of temperature regime on primary producers in Icelandic geothermal streams. Aquatic Botany, 95(4), 278-286. https://doi.org/10.1016/j.aquabot.2011.08. 003.

Hoffmann, A. A., \& Sgrò, C. M. (2011). Climate change and evolutionary adaptation. Nature, 470(7335), 479-485. https://doi.org/10.1038/nat ure09670. 
Ibáñez, I., Primack, R. B., Miller-Rushing, A. J., Ellwood, E., Higuchi, H., Lee, S. D., ... Silander, J. A. (2010). Forecasting phenology under global warming. Philosophical Transactions of the Royal Society of London B: Biological Sciences, 365(1555), 3247-3260. https://doi.org/10. 1098/rstb.2010.0120.

Inouye, D. W. (2000). The ecological and evolutionary significance of frost in the context of climate change. Ecology Letters, 3(5), 457-463. https://doi.org/10.1046/j.1461-0248.2000.00165.x.

Inouye, D. W., \& McGuire, A. D. (1991). Effects of snowpack on timing and abundance of flowering in Delphinium nelsonii (Ranunculaceae): Implicationsn for climate change. American Journal of Botany, 78(7), 997-1001. https://doi.org/10.2307/2445179.

IPCC. (2014). Climate Change 2014: Synthesis Report. In Core Writing Team, R. K. Pachauri, \& L. A. Meyer (Eds.), Contribution of Working Groups I, II and III to the fifth assessment report of the intergovernmental panel on climate change (151 pp). Geneva, Switzerland: IPCC.

Kollmann, J., \& Bañuelos, M. J. (2004). Latitudinal trends in growth and phenology of the invasive alien plant Impatiens glandulifera (Balsaminaceae). Diversity and Distributions, 10, 377-385. https://doi.org/10. 1111/j.1366-9516.2004.00126.x

Körner, C. (2007). The use of 'altitude' in ecological research. Trends in Ecology \& Evolution, 22(11), 569-574. https://doi.org/10.1016/j.tree. 2007.09.006.

Kristinsson, H. G. (1998). A guide to the flowering plants and ferns of Iceland, 2nd Reviseded edn. Reykjavík, Iceland: Mal Og Menning.

Lande, R., \& Arnold, S. J. (1983). The measurement of selection on correlated characters. Evolution, 37(6), 1210-1226. https://doi.org/10. $2307 / 2408842$

Lavergne, S., Mouquet, N., Thuiller, W., \& Ronce, O. (2010). Biodiversity and climate change: Integrating evolutionary and ecological responses of species and communities. Annual Review of Ecology, Evolution, and Systematics, 41(1), 321-350. https://doi.org/10.1146/annurev-ec olsys-102209-144628.

Leblans, N. I. W., Sigurdsson, B. D., Vicca, S., Fu, Y., Penuelas, J., \& Janssens, I. A. (2017). Phenological responses of Icelandic subarctic grasslands to short-term and long-term natural soil warming. Global Change Biology, 23(11), 4932-4945. https://doi.org/10.1111/gcb. 13749.

Linderholm, H. W. (2006). Growing season changes in the last century. Agricultural and Forest Meteorology, 137(1), 1-14. https://doi.org/10. 1016/j.agrformet.2006.03.006.

Medan, D., Montaldo, N. H., Devoto, M., Maniese, A., Vasellati, V., Roitman, G. G., \& Bartoloni, N. H. (2002). Plant-pollinator relationships at two altitudes in the Andes of Mendoza, Argentina. Arctic, Antarctic, and Alpine Research, 34(3), 233-241. https://doi.org/10.1080/ 15230430.2002 .12003490$.

Menzel, A., Sparks, T. H., Estrella, N., \& Roy, D. B. (2006). Altered geographic and temporal variability in phenology in response to climate change. Global Ecology and Biogeography, 15(5), 498-504. https://doi. org/10.1111/j.1466-822X.2006.00247.x.

Merilä, J., \& Hendry, A. P. (2014). Climate change, adaptation, and phenotypic plasticity: The problem and the evidence. Evolutionary Applications, 7(1), 1-14. https://doi.org/10.1111/eva.12137.

Munguía-Rosas, M. A., Ollerton, J., Parra-Tabla, V., \& De-Nova, J. A. (2011). Meta-analysis of phenotypic selection on flowering phenology suggests that early flowering plants are favoured. Ecology Letters, 14 (5), 511-521. https://doi.org/10.1111/j.1461-0248.2011.01601.x.

Nakagawa, S., \& Schielzeth, H. (2013). A general and simple method for obtaining $\mathrm{R}^{2}$ from generalized linear mixed-effects models. Methods in Ecology and Evolution, 4, 133-142.

O'Gorman, E. J., Benstead, J. P., Cross, W. F., Friberg, N., Hood, J. M., Johnson, P. W., ... Woodward, G. (2014). Climate change and geothermal ecosystems: Natural laboratories, sentinel systems, and future refugia. Global Change Biology, 20(11), 3291-3299. https://doi. org/10.1111/gcb.12602.
Olsson, K., \& Ågren, J. (2002). Latitudinal population differentiation in phenology, life history and flower morphology in the perennial herb Lythrum salicaria. Journal of Evolutionary Biology, 15(6), 983-996. https://doi.org/10.1046/j.1420-9101.2002.00457.x.

Parmesan, C. (2006). Ecological and evolutionary responses to recent climate change. Annual Review of Ecology, Evolution, and Systematics, 37 (1), 637-669. https://doi.org/10.1146/annurev.ecolsys.37.091305. 110100.

Parmesan, C., \& Yohe, G. (2003). A globally coherent fingerprint of climate change impacts across natural systems. Nature, 421(6918), 3742. https://doi.org/10.1038/nature01286.

Perron, N. S. (2017). Warming responses of two native Icelandic species, Ranunculus acris and Thymus praecox ssp. arcticus in geothermal areas (MsC Thesis). Retrieved from https://skemman.is/handle/1946/ 27751

Price, M. V., \& Waser, N. M. (1998). Effects of experimental warming on plant reproductive phenology in a subalpine meadow. Ecology, 79(4), 1261-1271. https://doi.org/10.1890/0012-9658(1998) 079[1261: EOEWOP]2.0.CO;2

R Core Team. (2018). R: A language and environment for statistical computing. Vienna, Austria: R Foundation for Statistical Computing. http://www.R-project.org/

Richardson, J. L., Urban, M. C., Bolnick, D. I., \& Skelly, D. K. (2014). Microgeographic adaptation and the spatial scale of evolution. Trends in Ecology \& Evolution, 29(3), 165-176. https://doi.org/10.1016/j.tree. 2014.01.002

Robinson, S. I., McLaughlin, Ó. B., Marteinsdóttir, B., \& O'Gorman, E. J. (2018). Soil temperature effects on the structure and diversity of plant and invertebrate communities in a natural warming experiment. Journal of Animal Ecology, 634-646, https://doi.org/10.1111/13652656.12798@10.1111/(ISSN)1365-2656.Global_Change_Ecology JANE2018

Rossiter, M. (1996). Incidence and consequences of inherited environmental effects. Annual Review of Ecology and Systematics, 27(1), 451476. https://doi.org/10.1146/annurev.ecolsys.27.1.451

Saemundsson, K. (1967). Vulkanismus und tektonik des Hengill-Gebietes in Südwest-Island. Acta Naturalia Islandica, 2, 1-105.

Saemundsson, K. (1992). Geology of the Thingvallavatn Area. Oikos, 64 (1/2), 40-68. https://doi.org/10.2307/3545042

Saemundsson, K. (1995). Geological map of the Hengill area 1:50,000. Reykjavík, Iceland: Orkustofnun.

Siepielski, A. M., DiBattista, J. D., \& Carlson, S. M. (2009). It's about time: The temporal dynamics of phenotypic selection in the wild. Ecology Letters, 12(11), 1261-1276. https://doi.org/10.1111/j.1461-0248. 2009.01381.x

Skelly, D. K. (2004). Microgeographic countergradient variation in the wood frog, Rana Sylvatica. Evolution, 58(1), 160-165. https://doi.org/ 10.1111/j.0014-3820.2004.tb01582.x

Soularue, J.-P., \& Kremer, A. (2014). Evolutionary responses of tree phenology to the combined effects of assortative mating, gene flow and divergent selection. Heredity, 113(6), 485-494. https://doi.org/10. 1038/hdy.2014.51

Stinchcombe, J. R., Rutter, M. T., Burdick, D. S., Tiffin, P., Rausher, M. D., \& Mauricio, R. (2002). Testing for environmentally induced bias in phenotypic estimates of natural selection: Theory and practice. The American Naturalist, 160(4), 511-523. https://doi.org/10.1086/ 342069

Toftegaard, T., Posledovich, D., Navarro-Cano, J. A., Wiklund, C., Gotthard, K., \& Ehrlén, J. (2016). Variation in plant thermal reaction norms along a latitudinal gradient - more than adaptation to season length. Oikos, 125(5), 622-628. https://doi.org/10.1111/oik.02323

Visser, M. E. (2008). Keeping up with a warming world; assessing the rate of adaptation to climate change. Proceedings of the Royal Society of London B: Biological Sciences, 275(1635), 649-659. https://doi.org/10. 1098/rspb.2007.0997 
Weis, A. E. (2015). On the potential strength and consequences for nonrandom gene flow caused by local adaptation in flowering time. Journal of Evolutionary Biology, 28(3), 699-714. https://doi.org/10. 1111/jeb.12612

Weis, A. E., \& Kossler, T. M. (2004). Genetic variation in flowering time induces phenological assortative mating: Quantitative genetic methods applied to Brassica rapa. American Journal of Botany, 91(6), 825836. https://doi.org/10.3732/ajb.91.6.825

Wolkovich, E. M., Cook, B. I., Allen, J. M., Crimmins, T. M., Betancourt, J. L., Travers, S. E., ... Cleland, E. E. (2012). Warming experiments underpredict plant phenological responses to climate change. Nature, 485(7399), 494-497. https://doi.org/10.1038/nature11014
Zakharova, O. K., \& Spichak, V. V. (2012). Geothermal fields of Hengill Volcano, Iceland. Journal of Volcanology and Seismology, 6(1), 1-14. https://doi.org/10.1134/S074204631201006X

How to cite this article: Valdés A, Marteinsdottir B, Ehrlén J. A natural heating experiment: Phenotypic and genotypic responses of plant phenology to geothermal soil warming. Glob Change Biol. 2018;00:1-9. https://doi.org/10.1111/ $\underline{\text { gcb.14525 }}$ 